\title{
USE OF ESA EARTH OBSERVATION EDUCATIONAL RESOURCES IN VOCATIONAL EDUCATION AND TRAINING - LIFELONG LEARNING: TOWARDS STEM PROMOTION AND DEVELOPMENT OF SKILLS
}

\author{
Mouratidis A. ${ }^{1,2}$ and Koutsoukos M. ${ }^{3}$ \\ ${ }^{I}$ Consultant to the European Space Agency (ESA), ESA/ESRIN, Via Galileo Galilei, 00044, \\ Frascati, Italy, antonios.mouratidis.esa.int@gmail.com \\ ${ }^{2}$ Aristotle University of Thessaloniki, Department of Physical \& Environmental Geography, \\ 54124, Thessaloniki,Greece,amourati@geo.auth.gr \\ ${ }^{3}$ School of Pedagogical and Technological Education (ASPETE), 1 Andrea Kalvou, 50100, \\ Kozani, Greece, koutsoukos.marios@gmail.com
}

\begin{abstract}
Vocational Education and Training (VET) and Life-Long Learning (LLL), stand at the forefront of Europe's strategic policies in Education, in response to the lack of students' interest in STEM and the emerging needs for new skills in the labour market. Space can be a particularly useful platform for attracting students to STEM, environmental as well as topics related to geospatial information, as many state-of-the-art technologies used in everyday life are space-based, while space seems to also be creating a genuine interest among most learners. This study focuses on the plethora of European Space Agency (ESA) Earth Observation (EO) education material readily accessible, at no cost and available in several languages. Undertaking the effort to optimizelextend the use of these existing EO educational resources also in VET and LLL, for promoting STEM subjects, as well as for the development of green and geospatial skills, would be to the mutual benefit of both ESA and the European Union. Finally, it is proposed that an assessment of the utility and potential for the overall ESA Education resources (other than EO), but also of other Space Agencies and relevant institutions active in space education, in VET and LLL would be of particular interest.
\end{abstract}

Keywords: Green skills, Geospatial skills, Learning outcomes, Space, Education.

\section{Пврі́ $\lambda \psi \psi \eta$}

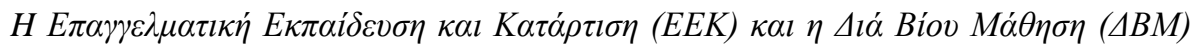

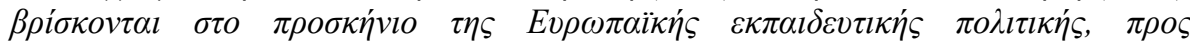

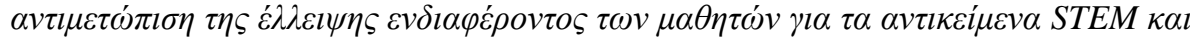

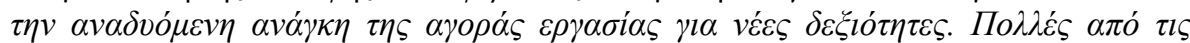

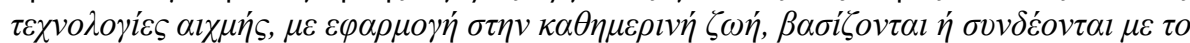

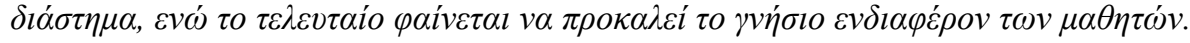

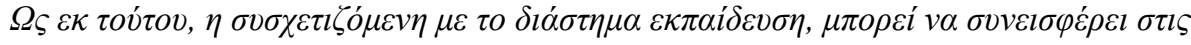

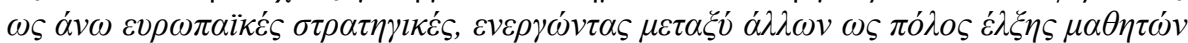

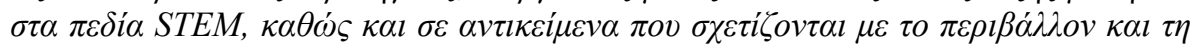

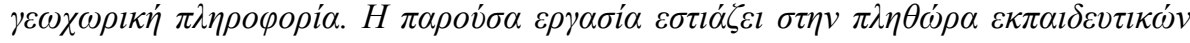

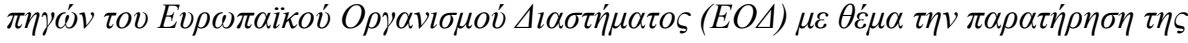




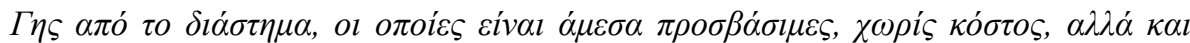

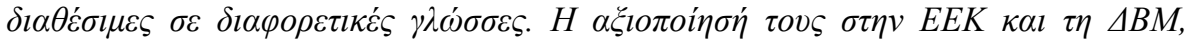

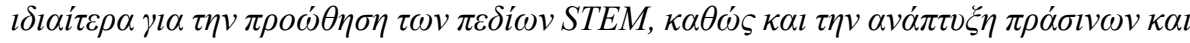

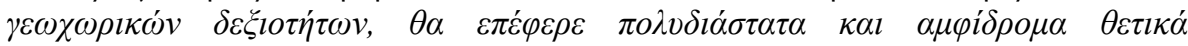

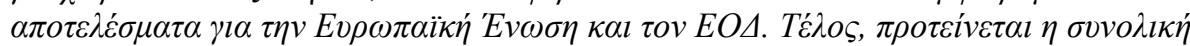

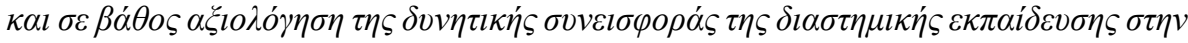
EEK $\kappa \alpha l \tau \eta \triangle B M$.

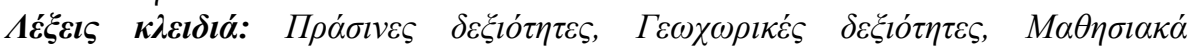

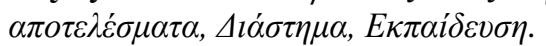

\section{Introduction}

\subsection{Background}

The term "Earth Observation (EO)" is used to describe the capacity to look at, explore, map and monitor our planet, using the ability to fly satellites into space. EO has changed our lives in many ways, as it is being used in meteorology and climate studies, environmental protection and natural disasters management, but also in map-making, popular applications on the internet or on mobile devices etc. Among these implications, the evolution and developments in EO have also been to a great benefit for Education, through the diverse usage of an impressive amount and variety of satellite images and data for planet Earth, being acquired from space.

Europe's gateway to space is the European Space Agency (ESA), an international organisation with currently 22 Member States (Austria, Belgium, Czech Republic, Denmark, Estonia, Finland, France, Germany, Greece, Hungary, Ireland, Italy, Luxembourg, The Netherlands, Norway, Poland, Portugal, Romania, Spain, Sweden, Switzerland and the United Kingdom). Latvia, Slovenia and Slovakia are European Cooperating States. Other countries in Europe (Bulgaria, Cyprus, Lithuania and Malta) have also signed cooperation agreements with ESA, while Canada sits on ESA's governing Council under a special agreement. ESA's mission is to shape the development of Europe's space capability and ensure that relevant investments continue to deliver benefits to the citizens of Europe and the world. ESA is heavily involved in environmental monitoring and climatic change studies, within two major EO initiatives; GMES and CCI. Global Monitoring of the Environment and Security (GMES) is the European Programme for the establishment of a European capacity for Earth Observation. GMES is a partnership between ESA and the EU, aiming at providing data to support Europe's policy goals on environment and security for the next 25 years. Climate Change Initiative (CCI) is an effort to establish a complete and accurate historical archive of climatic variables.

ESA also stands at the forefront of space education. Since 1975, when ESA was created, one of its most important tasks has been to inform the public about the latest advances and discoveries in the space field and to develop programmes that will inspire young people to pursue careers in science and technology. ESA's Education Office is responsible for the Agency's corporate education programme. The aim is to help young Europeans gain and maintain an interest in science and technology, with the long-term objectives of contributing towards the creation of a knowledge-based society and ensuring the existence of a qualified workforce for the Agency that will guarantee Europe's continued leadership in space activities. This is achieved by organising various activities designed for specific age groups, keeping the educational community informed about the new developments, as well as providing inspirational materials that assist teachers and students with the learning process.

While through its educational resources ESA contributes to the effort for ensuring the future employment of a highly qualified workforce for both ESA and the European industry, the latter, together with scientific institutions, support many thousands of jobs and contribute billions of euros to national economies. Additionally, there are thousands of employer organisations offering employment opportunities in the domain of spatial information services, an industry also worth 
billions of euro annually and growing year by year. Earth Observation/Remote Sensing data and techniques, along with Geographic Information Systems (GIS), Global Navigation Satellite Systems (GNSS), Cartography and Surveying, comprise the backbone of this sector. They involve gathering data about our world and its environment, producing maps, monitoring phenomena and measuring various parameters in the atmosphere, land and oceans. This includes physical and man-made features as well as other properties. After processing, the data collected is used by many different sectors, such as mining exploration, environmental monitoring, construction, land management and urban planning etc. Spatial Information Services and Surveying qualification pathways are found at University, as well as at Vocational Education and Training (VET) level.

VET is a type of public or private education that prepares trainees for jobs or careers at various levels; from a trade to a craft or a position in engineering (mechanical, electrical, civil, and architectural), computer science, safety-related professions, agriculture, social sciences, medicine, law etc. VET can be at the secondary (school-based or combined school and work-based) or postsecondary level (usually provided by a technological institute or a college). It is also divided into IVET (Initial Vocational Education and Training) and CVET (Continuous Vocational Education and Training), depending on whether it takes place after initial education and training or after entry into working life. Although rarely considered as part of higher education in its traditional definition, vocational education can in several cases be recognised as partial academic credit towards tertiary education (e.g., at a university). As the labour market becomes more specialized and economies demand a higher level of qualifications, the public and private investment in VET towards the anticipation of future skill needs is increasing.

In addition to VET, the concept of Lifelong Learning (LLL) involves the provision of education and training possibilities for everyone, regardless of their age. The focus of LLL is not only restricted to competitiveness and employability, but also extends to social inclusion, active citizenship and personal development (European Commission, 2006). CVET is for example part of LLL, as it may encompass any kind of education (general, specialised or vocational, formal or non-formal, etc.). LLL can take place in a variety of environments, both inside and outside formal education and training systems. LLL implies investing in people and knowledge; promoting the acquisition of basic skills, including digital literacy and broadening opportunities for innovative, more flexible forms of learning. The aim is to provide people of all ages with equal and open access high-quality learning opportunities and to a variety of learning experiences (Eurostat, 2015).

\subsection{Scope}

Europe has experienced a dramatic decline in the number of young people interested in science, technology, engineering or mathematics (STEM) subjects, both at secondary and post-secondary level. Moreover, the move towards an environmental-friendly economy demands the development of new competences such as "geospatial" and "green" skills. A lack of manpower and such skills adversely affects the related industry and employment markets, putting the whole future of the European knowledge-based society and economy at stake. Therefore, several coordinated actions are being taken by the EU, in order to offset this shortage.

As a contribution to these efforts, this paper is an initial approach concerning the use of ESA EO educational resources in VET and LLL. In particular, it explores the potential of exploiting existing educational material (on-line, classical, software and applications, data) and education-related opportunities in EO for enlarging Europe's capacities and assisting the European Union (EU) Member States in the implementation of policies in education and training, towards the development and promotion of geospatial and green skills, in a STEM context.

To this end, a short summary of the background, strategies and current relevant trends in VET and LLL in Europe is firstly presented. Subsequently, the study focuses on the prospects of maximizing the exploitation of the various ESA EO education resources in VET and LLL. The investigation 
concludes with the expected EU-ESA benefits of such a synergy, as well as with recommendations, in the direction of a knowledge-based and environmental-friendly economy.

\section{VET and LLL in Europe}

\subsection{Education and Training 2020 - VET and LLL}

In 2009, the "Education and Training 2020" (ET 2020) strategic framework for European cooperation in education and training was drawn up (European Union, 2009). Building on its predecessor, the "Education and Training 2010" (ET 2010) work programme launched in 2001, it provides common strategic objectives for EU Member States, including a set of principles for achieving these objectives, as well as common working methods. Since then, the economic and political context has changed, creating new uncertainties and constraints. The EU had to take further action against the worst financial and economic crisis in its history and has agreed on "Europe 2020".

Europe 2020 (European Commission, 2010a) is the EU's growth strategy for the coming decade, in the direction of becoming a smart, sustainable and inclusive economy. These three mutually reinforcing priorities should help the EU and the Member States deliver high levels of employment, productivity and social cohesion. More specifically, the EC has set five ambitious objectives (employment, innovation, education, social inclusion and climate/energy) to be reached by 2020 . Each Member State has adopted its own national targets in each of these areas, while concrete actions at EU and national levels underpin the strategy. ET 2020 (European Union, 2012), as a key instrument to modernise education and training, can make a major contribution to achieving Europe 2020 's objectives. Nevertheless, the EC has suggested to review and adjust the working arrangements under ET 2020 that were devised before Europe 2020, in order to achieve better alignment between the two frameworks.

In this context, VET is vital in preparing individuals for today's society and ensure Europe's future competitiveness and innovation. VET is faced with challenges, such as intensified global competition, high numbers of low-skilled workers and an ageing population. Actions to improve VET help to provide the skills, knowledge and competences needed in the labour market. As such, they are an essential part of the ET 2020 work programme.

The EC acts together with EU Member States and other countries to strengthen VET across Europe. The "Copenhagen Process", established in 2002, lays out the basis for co-operation in VET, with 33 European countries involved. In June 2010 (European Commission, 2010b), the European Commission presented a 10 year vision for the future of VET in the Communication "A New Impetus for European cooperation in Vocational Education and Training to support the Europe 2020 strategy". In December 2010 (European Commission, 2010c) participants of the Copenhagen Process met in Belgium to agree on common objectives in vocational training for 2011-2020, as well as on an action plan for the first years with concrete measures at national level and support at European level. The package of these objectives and actions is known as "the Bruges Communiqué".

Regarding LLL in Europe, the European Commission's Lifelong Learning Programme (LLP) aims at providing education and training opportunities for all people and at all stages of their lives. This is pursued by enabling them to take part in stimulating learning experiences, as well as helping to develop the education and training sector across Europe. With a budget of nearly 7 billion euro for the period 2007-2013, LLP funds a range of actions, including exchanges, study visits and networking activities. Projects are intended not only for individual students and learners, but also for teachers, trainers and all others involved in education and training. The sub-programmes of LLL, which fund projects at different levels of education and training are: (i) "Comenius" for schools, (ii) "Erasmus" for higher education, (iii) "Leonardo da Vinci" for VET and "Grundtvig" for adult education. Other projects in areas that are relevant to all levels of education, such as language learning, information and communication technologies, policy co-operation and dissemination and exploitation of project results are funded through the "transversal" part of the programme. In 
addition, the programme includes "Jean Monnet actions", which stimulate teaching, reflection and debate on European integration, involving higher education institutions worldwide.

For the ET 2020 objectives in education and social inclusion to be achieved, LLL is of paramount importance. Additionally, the implementation of European cooperation in education and training from a lifelong learning perspective is included within the set of principles, which should be observed when working towards the established objectives.

\subsection{Learning Outcomes Approach}

The term "learning outcomes" is defined as "statements of what a learner knows, understands and is able to do on completion of a learning process". This implies the evaluation of knowledge, irrespective of how, when and where it was acquired (Cedefop, 2010b).

The concept of "outcomes" is not new to education and training; what is now evident is its greatly increased prominence over the past few years in national and European VET policies and in any discussion about curriculum reform. Curriculum is increasingly seen by stakeholders as a dynamic framework guiding teaching and learning processes and as a steering mechanism for quality. It features in key European policy documents as a new consensus for contributing to Europe 2020. Findings of empirical research (Cedefop, 2012b) widely recognise that curriculum relevance is a condition sine qua non, not only for improving the human capital potential of education and training graduates, but also for retaining learners in education and training systems. The endemic irrelevance of curriculum may be one of the greatest obstacles to successfully matching education and training provision to learner and labour market needs.

The adoption of a learning outcomes approach when developing curricula is seen by many European countries as an effective way to avoid such potential mismatches and promote active learning and inclusive teaching. Outcome-oriented curricula can offer a valuable platform for bridging the worlds of education, training and work, providing a common language between competences acquired in learning, the needs of occupations and the labour market. Although curricula based on learning outcomes are not automatically guaranteed to succeed, they bare the potential of important benefits for VET providers and employers, teachers and learners (Cedefop, 2010b).

\subsection{Green Skills}

According to Cedefop (2010a, 2012a, 2012b), "Green skills" refer to the "the knowledge, abilities, values and attitudes needed to live in, develop and support a society, which reduces the impact of human activity on the environment". Climate change, globalisation and rapid technological evolution are the main drivers for important shifts in labour markets and skills needs. "Green jobs" and occupations in "green" sectors that encourage eco-friendly production and consumption are meant not only to create a more sustainable economy, but also to generate quality jobs. This is in line with the Europe 2020 strategy and further recommendations from the EC, which identify green economy as the main area of future job creation. The EU's strategy on climate change and the development of a cleaner, more resource-efficient Europe will affect the labour market: new regulations, new materials and new technologies will change job content. In many Member States this shift is already under way and new green occupations are emerging.

Availability of skills for green jobs plays a crucial role in triggering change and facilitating just and timely transitions. Thus, well-timed reformulation of qualifications and course content becomes a major issue, as the move to a green economy is generating a need for new skills at an accelerating pace and scale.

As these novel "green competences" are usually related to new technologies, the deficit in available technical skills is also strongly linked to the lack of interest and to the few young people studying STEM (Cedefop 2010a, 2012b). In this context, the need for improvements in the capacity of existing education, training and qualification systems to respond to environmentally-driven skills needs has been broadly recognized in all Member States. 


\subsection{Geospatial Skills}

According to Mouratidis (2015), skills that can be characterized as "(geo)spatial" mainly include fundamental notions of classical Geography/Cartography, together with the use of Information and Communications Technology (ICT). The materials used which may be in analog or digital format, may concern deskwork and/or fieldwork applied directly in the "real" world. Thus, geospatial skills may indicatively include: (i) Designing diagrams, (ii) Ability to implement the basic elements of map-making (e.g. scale, orientation, legend, reference system), (iii) Use of appropriate symbols for representing spatial phenomena, (iv) Reading/finding direction and orientation, (v) Estimating and measuring dimensions (distance, surface and volume), (vi) Ability for perspective perception and visualization of space, (vii) Reproduction/mapping of space, using images or real-time observations, (viii) Recognition of spatial patterns of objects or phenomena, as well as their temporal variations in space, (ix) Collecting, classifying, evaluating, processing, analyzing-interpreting, presenting and overall management of data/information with spatial reference, (x) Basic use of satellite images, GNSS and GIS.

The lack of human resources with geospatial skills affects negatively the industry, employment and markets, putting the future of the European knowledge-based society and economy at risk.

As the "spatially enabled societies" are considered an essential element for the present and future in European and worldwide, the role of education, training, capacity building, but also of outreach activities for geospatial technology is fundamental. The purpose is to feed society with adequately qualified graduates - especially in VET, as well as in Tertiary/University education (graduates and post-graduates). Nevertheless, the foundations of this effort lie in attracting the interest of youngsters, already at primary and secondary education level. Additionally, to the end of realizing a geospatially aware and active society, the broader domain of geography, in its modern form, needs to be extensively communicated to the general public (role of outreach).

In Europe, this is evident through major initiatives and investments, such as e.g. the INSPIRE Directive for establishing an infrastructure for (geo)spatial information; the Copernicus programme, dedicated to satellite and in-situ data collection for a global monitoring of environment and for security purposes; the Galileo GNSS programme, for providing a highly accurate global positioning service under civilian control. Implications and applications of these endeavours are practically endless, extending from environmental mapping and monitoring of climate change, to safety and emergency response, transportation, navigation and overall efficient management of resources, just to name a few. Along the same lines, there are other on-going geospatial education efforts, studies and opportunities, mainly in Europe, through programmes and initiatives such as "Geo Skills Plus", "SPACIT", "digital-earth.eu" $\kappa \alpha \imath$ "GEOTHINK".

Nevertheless, apart from these dedicated actions, there is a plethora of readily available educational, informational and other appropriate material, in the broad field of geospatial technology. One of these sources is ESA, an organization which, among other space-related domains, is active in EO from Space.

Although the content of these educational resources has not been specifically intended for VET and LLL purposes, it does provide a wealth of educational possibilities. Yet, this rich material has merely been used from the space-related scientific/academic community (at university level) and largely remains unexploited in VET and LLL.

\section{ESA EO Education in VET and LLL}

\subsection{Overview}

ESA EO is one of the components of ESA education, training and capacity building, participating to several of the numerous educational activities (hands-on projects, support to teachers, international cooperation activities, opportunities for students, outreach initiatives etc.). The scope 
of these activities ranges from high level training in state-of-the-art processing for the next generation of Principal Investigators to more general outreach activities and EO education for schools. The ESA EO Education and Training website provides an all-in-one portal that supplies information about these activities and enables access to resources produced in their framework. The majority of EO education material is directly related to geospatial technology and "green topics", as it concerns climatic change, environmental protection, prediction, monitoring and management of natural disasters and safeguarding of our planet. It is also particularly important to note that a large percentage of the EO educational material is available in several European languages.

\subsection{On-line material and applications}

ESA EO education on-line material and web applications are items that bear the potential of reaching the largest possible audience (free of charge and easy access). Such ESA EO education resources are the following: (i) The main page for ESA EO education, which contains or gives links to all the on-line material (lectures, data and exercises) developed for ESA EO courses - most of them with a strong environmental component; (ii) "Eduspace" (http://www.esa.int/SPECIALS/Eduspace_EN/); a website aiming to provide a learning and teaching tool to secondary school students and teachers, across the various educational systems in Europe. It is meant to be an entry point to a widespread visibility of Earth observation applications for education and training; (iii) "Interactive Meteosat" (http://www.asrc.ro/imeteosat_beta/geostationary_view.php); a web-based interactive application dedicated to meteorology. It contains updated (daily) meteorological images and promotes the cooperation between educational institutions (e.g. secondary schools); (iv) Teacher's pack in Earth Observation and Remote Sensing (e-version); 11 worksheets on the topic "Watching over the Earth", (v) Science Education via EO for High Schools (SEOS); 15 internet-based e-Learning tutorials on selected topics in EO, for using remote sensing in science education curricula in high schools. SEOS was funded under the 6th Framework Programme of the EC and implemented by 11 partners from different European countries in cooperation with ESA; (vi) The ESA multimedia gallery; it displays the best visual material (images, videos, animations etc.) of the ESA portal, among which many EO and environment-related subjects.

Additionally, ESA is in the process of developing EO material and didactical applications for mobile devices, addressed to the general public. Although these would be particularly used by young people, they would be in practice suitable for any audience.

\subsection{Classical material}

Publications (such as Atlases, manuals, handbooks, kits etc.), are categorized under "classical material". They are addressed to secondary and post-secondary level. Some of these items have the constraint of the limited number of copies that can be printed and distributed for free. The most prominent items are: (i) ESA School Atlas; provides a vast array of environmental elements (also normally invisible ones) and explains the importance of sustainable development. It is accompanied by a teachers' handbook, a digital version on 2 DVD's and is also connected to Eduspace through its case studies and exercises; (ii) EO posters; addressed to different audiences, with mostly environmental context, in order to increase awareness, (iii) Teacher's pack in EO and Remote Sensing (hard copy).

\subsection{Software and data}

ESA provides most of its data free of charge and develops or supports the development of open source/freeware educational software. This category includes: (i) "Leoworks"; a purely educational open source software for inspecting and analysing satellite images. It represents the main tool for demonstrating EO techniques at secondary or post-secondary level. It is used in relation to Eduspace or in the frame of ESA training courses for teachers and learners. It also includes extensive Geographical Information Systems (GIS) functionalities. GIS skills are widely appreciated in the labour market, as GIS has become an indispensable tool for geographical information management and decision making processes in almost all sectors; (ii) "Bilko"; supported by UNESCO and ESA, 
the Bilko software is accompanied by a number of tutorials, lessons and modules that demonstrate different applications of remote sensing; (iii) Satellite images and data; available under different data policies and by various access mechanisms. Most of the data can be accessed for free after registration.

ESA also supports the development of more sophisticated software and toolboxes, which are addressed to more advanced users (university level).

\subsection{European Space Education Resource Office}

In recent years, ESA has been supporting the European Space Education Resource Office (ESERO) project. ESERO envisages the establishment of contact / resource centres that are manned by education experts and integrated into national educational systems and networks. A variety of educational materials has also been developed for students of various ages. The ESERO project addresses the motivation of young people to enhance their literacy in STEM, including associated applications, using the genuine fascination for space related themes - and EO is one of them. The ESERO contact point implements an annual series of teacher (primary and secondary) training sessions in collaboration with national partners, already active in STEM education. They use and disseminate existing ESA/ESERO education materials, and if appropriate, develop specific resources tailored to the needs of the education community. The ESERO office also organises national ESERO teacher conferences for secondary and primary education.

The first ESERO contract was signed in The Netherlands in late 2005 with NEMO (the National Science and Technology Centre) in Amsterdam. Currently there are 9 offices up and running, namely in Belgium, Czech Republic, Ireland, Netherlands, Nordic ESERO (Denmark, Finland, Sweden and Norway), Poland, Portugal, Romania and UK.

\subsection{Training activities for educators and learners}

ESA organises several training activities for multiple purposes and audiences. Such events are: (i) Training courses addressed to secondary school teachers (e.g. the ESA summer workshop for secondary school teachers ); typically organised over one or few days, where the basic notions of EO and remote sensing are given to groups of teachers, along with presentations and possibly computer demonstrations and computer practicals of the different relevant tools developed by ESA; (ii) Dedicated or ad-hoc (depending on availability of resources) training courses for universities or professionals (e.g. for coastguard officers or other safety or security-related professions); addressed to ESA Member or Cooperating States; (iii) Workshops (university level); related to EO, devoted to teachers, professors or trainers, selected at European or international level. These workshops normally include oral talks, fieldtrips, posters, and may contain computer labs and training courses; (iv) Capacity building workshops in developing countries.

\subsection{Training activities for educators and learners}

ESA organises several training activities for multiple purposes and audiences. Such events are:

ESA EO education further involvement includes: (i) Participation to the Committee on Earth Observation Satellites (CEOS) - Working Group on Capacity Building \& Data Democracy (WGCapD). The CEOS strategy for EO education and training is the creation of an effective coordination and partnership mechanism among CEOS agencies and institutions offering education and training; (ii) Organization of events for schools and universities (depending on available resources); school visits at ESA facilities, open days etc.; (iii) Participation to events with a promotional and communicational component: e.g. to educational TV programs.

Apart from purely educational activities, in combination with industry, EO is involved in actions targeted to foster and promote innovation, creativity and entrepreneurship. GMES Masters competition is a characteristic and prestigious paradigm of cooperation between ESA and the EC, 
concerning technology transfer and support to start-ups that build their business on utilisation of space technologies and techniques for non-space applications.

\section{Conclusions and Recommendations}

Supporting the use of ESA EO resources in VET and LLL, in particular for the promotion of STEM and the development of green skills would bring along positive outcomes on several fronts. Some benefits for VET and LLL in the EU would be:

- The modernization of education and training systems, including the provision of technical skills (e.g., GIS), which are widely appreciated in the labour market.

- Support of the learning outcomes approach, in the sense of providing tools to evaluate what a learner has learned after a training session.

- Making VET a more attractive option for both young people and adults - reducing the level of students dropping out of school early.

- Inclusion of emerging and state-of-the-art technologies.

- Promoting enhanced European (ESA-EU) cooperation in VET.

- Access to freely available material, in several languages, suitable for promoting STEM subjects, geospatial and green skills.

- Development of links and informal pathways between vocational training activities and university educational systems.

- Encouraging the establishment of a culture of creative, innovative and entrepreneurial thinking.

- Overall contribution to the Europe 2020 strategy for education and employment.

On the other end, there would be significant benefits for ESA as well, i.e.: (i) Getting more people involved and use the ESA EO education resources, especially existing on-line material, which does not deplete ESA of its educational resources; (ii) A good promotion for the overall ESA education program; (iii) Increasing the overall visibility of ESA and helping it extend to a wider public; (iv) Attract more future employees for the Agency (diversity of the background of ESA employees denotes that no topics are excluded and part of its workforce will be coming from VET); (v) All of the above, at minimum extra effort and resources (mainly only in terms of communicating the existing material) for the Agency.

Overall, there is a plethora of ESA EO education material readily accessible, addressing STEM and environmental topics; most of it is at no cost and available in several languages. VET and LLL providers should be informed about the existence of these resources and attempt to make use of them, by adapting it to their specific needs, with the assistance and expertise of ESA, where applicable. After all, this is in line with the current policies ("Bruges Communiqué"), encouraging VET providers to "...collaborate with innovative enterprises, design centres, the cultural sector and higher education institutions in forming knowledge partnerships...", in the direction of helping them "...gain valuable insight into new developments and competence needs and to develop professional excellence and innovation...".

In the future, technology will bring in new input data and qualification requirements are bound to change, forcing education and training policies to be re-adapted. Nevertheless, establishing strategies for strengthening European cooperation in education and training can significantly assist in responding to the challenges in a timely and effective way. Undertaking the effort to optimize the use of existing educational resources within ESA for promoting STEM subjects and for the development of "green" skills in Europe, can be a strategic objective to the mutual benefit of ESA and the EU. 
Although this preliminary study is restricted to Earth Observation, it may well be also applicable to other ESA education domains such as Navigation, Science and Robotic Exploration, Human Spaceflight and Operations etc., but also to other sources of Space education, such as national space agencies and related international organizations. Consequently, a more detailed assessment of the utility and potential for the overall Space education resources in Vocational Education and Training and Lifelong Learning would be of interest, in close cooperation with VET experts, providers and other stakeholders.

\section{References}

Cedefop, 2012a. Green skills and environmental awareness in vocational education and training: Synthesis report, Luxembourg, Publications Office of the European Union.

Cedefop, 2012b. A strategy for green skills? Briefing note 9067, 4p, doi: 10.2801/16037.

Cedefop, 2010a. Skills for green jobs: European synthesis report, Luxembourg, Publications Office of the European Union.

Cedefop, 2010b. Learning outcomes approaches in VET curricula: A comparative analysis of nine European countries, Luxembourg, Publications Office of the European Union.

European Commission, 2010a. Europe 2020: A strategy for smart, sustainable and inclusive growth, COM (2010) 2020.

European Commission, 2010b. A new impetus for European cooperation in Vocational Education and Training to support the Europe 2020 strategy, COM (2010) 296.

European Commission, 2010c. The Bruges Communiqué on enhanced European Cooperation in Vocational Education and Training for the period 2011-2020.

European Commission, 2006. Adult learning: It is never too late to learn, COM (2006) 614.

European Union, 2012. 2012 Joint Report of the Council and the Commission on the implementation of the Strategic Framework for European cooperation in education and training (ET 2020), Official Journal of the European Union, C 70/9 - C 70/18.

European Union, 2009. Council conclusions of 12 May 2009 on a strategic framework for European cooperation in education and training ('ET 2020'), Official Journal of the European Union, C $119 / 2$ - C 119/10.

Eurostat, 2015. Lifelong learning statistics - Data from June 2015.

Mouratidis, A., 2015. Exploitation of the European Space Agency Earth observation data and technology in VET and LLL, thesis submitted to the School of Pedagogical and Technological Education (ASPETE) in partial fulfilment of the requirements for the Certificate of Specialization in Counselling and Guidance (PESYP), ASPETE, Greece (in Greek). 